\title{
Vitamin $D$ deficiency is associated with impaired disease control in asthma-COPD overlap syndrome patients
}

This article was published in the following Dove Press journal:

International Journal of COPD

24 September 2015

Number of times this article has been viewed

\author{
Balázs Odler' \\ István Ivancsó' \\ Vivien Somogyi \\ Kálmán Benke ${ }^{2}$ \\ Lilla Tamási ${ }^{1}$ \\ Gabriella Gálffy' \\ Balázs Szalay ${ }^{3}$ \\ Veronika Müller' \\ 'Department of Pulmonology, ${ }^{2}$ Heart \\ and Vascular Centre, ${ }^{3}$ Department of \\ Laboratory Medicine, Semmelweis \\ University, Budapest, Hungary
}

Introduction: The association between vitamin $\mathrm{D}$ and clinical parameters in obstructive lung diseases (OLDs), including COPD and bronchial asthma, was previously investigated. As asthma-COPD overlap syndrome (ACOS) is a new clinical entity, the prevalence of vitamin D levels in ACOS is unknown.

Aim: Our aim was to assess the levels of circulating vitamin D (25-hydroxyvitamin D [25(OH)D]) in different OLDs, including ACOS patients, and its correlation with clinical parameters.

Methods: A total of 106 men and women (control, $n=21$; asthma, $n=44$; COPD, n=21; and ACOS, $n=20$ ) were involved in the study. All patients underwent detailed clinical examinations; disease control and severity was assessed by disease-specific questionnaires (COPD assessment test, asthma control test, and modified Medical Research Council); furthermore, 25(OH)D levels were measured in all patients.

Results: The 25(OH)D level was significantly lower in ACOS and COPD groups compared to asthma group ( $16.86 \pm 1.79 \mathrm{ng} / \mathrm{mL}$ and $14.27 \pm 1.88 \mathrm{ng} / \mathrm{mL}$ vs $25.66 \pm 1.91 \mathrm{ng} / \mathrm{mL})$. A positive correlation was found between $25(\mathrm{OH}) \mathrm{D}$ level and forced expiratory volume in 1 second $(r=0.4433$; $P<0.0001)$, forced vital capacity (FVC) $(r=0.3741 ; P=0.0004)$, forced expiratory flow between $25 \%$ and $75 \%$ of FVC $(r=0.4179 ; P<0.0001)$, and peak expiratory flow $(r=0.4846 ; P<0.0001)$ in OLD patient groups. Asthma control test total scores and the 25(OH)D level showed a positive correlation in the $\operatorname{ACOS}(r=0.4761 ; P=0.0339)$ but not in the asthma group. Higher COPD assessment test total scores correlated with decreased $25(\mathrm{OH}) \mathrm{D}$ in ACOS $(r=-0.4446$; $P=0.0495$ ); however, this was not observed in the COPD group.

Conclusion: Vitamin D deficiency is present in ACOS patients and circulating 25(OH)D level may affect disease control and severity.

Keywords: ACOS, obstructive lung disease, CAT

\section{Introduction}

COPD and bronchial asthma are obstructive lung diseases (OLDs) with high incidence and prevalence. COPD is a progressive inflammatory disorder mainly affecting the small airways. The disease is characterized by airway inflammation, increased airway resistance (Raw), fibrosis, mucus hypersecretion, and parenchymal lesions with reduced elastic recoil and loss of alveolar attachments, leading to airflow limitation. ${ }^{1}$ It has been estimated that $\sim 40$ million people in Europe are living with COPD and $\sim 60 \%$ are having significantly impaired lung function (stages II-IV). ${ }^{2}$

Bronchial asthma is also a chronic inflammatory disease of the airways characterized by variable and recurring symptoms, local inflammation, reversible airflow obstruction, and bronchospasm. ${ }^{3}$ Asthma is a prevalent chronic disease (affecting $~ 30$ million
Correspondence: Veronika Müller I I 25, Hungary

Tel +36 I 3559733

Fax +36 । 2142498

Email muller.veronika@med.semmelweisuniv.hu 
people in Europe) that, in approximately $50 \%$ of cases, is not optimally controlled, even in developed countries. Furthermore, it has a high burden of morbidity especially if not controlled. ${ }^{4}$

The asthma-COPD overlap syndrome (ACOS) has been defined as the coexistence of increased variability of airflow in a patient with incompletely reversible airway obstruction. ${ }^{5}$ According to the Global Initiative of Asthma (GINA), ACOS is not a single disease. Its risk factors are shared with asthma and COPD, including development in the later decades of life, airway hyper-responsiveness, often tobacco smoke exposure, and progressive loss of lung function. ACOS may also be characterized by more frequent and severe exacerbations as well as eosinophil and/or neutrophil cells in sputum as compared to asthma or COPD alone. ${ }^{3}$

In the recent years, the growing interest of the role of 25-hydroxyvitamin D $(25(\mathrm{OH}) \mathrm{D})$ in lung diseases is emerging. There are several studies showing that vitamin $\mathrm{D}$ deficiency is common in COPD and associated with worse lung function parameters. ${ }^{6-8}$ In asthma, higher vitamin $\mathrm{D}$ comes together with less exacerbations, and the supplementation of the vitamin may be effective in the prevention of the exacerbations. ${ }^{9}$ Moreover, high vitamin D levels were associated with improved lung function, better glucocorticoid response, and less airway hyperactivity in asthmatic patients. ${ }^{10}$ Both in COPD and asthma, vitamin D has the potential to influence the onset of the disease by impacting on the lung in utero and early in life. ${ }^{11-13}$ It is axiomatic that there has been an explosion of vitamin D research in chronic lung diseases; however, as ACOS is a new clinical appearance of OLDs, there are no available data in literature about the role of vitamin D in this entity and its possible role in disease pathogenesis.

In this study, we aimed to investigate the level of $25(\mathrm{OH}) \mathrm{D}$ in asthma, in COPD, and, especially, in ACOS patients. Additionally, in order to have a more complete view of the role of vitamin D in OLD, and especially in ACOS, its correlation with clinical parameters was also investigated.

\section{Methods}

\section{Ethical statement}

The study was reviewed and approved by an independent ethical committee of the institution (Semmelweis University Regional and Institutional Committee of Science and Research Ethics - TUKEB: 145/2012). Written informed consent was obtained from all subjects. Laboratory studies and interpretations were performed on coded samples lacking personal and diagnostic identifiers.

\section{Patient recruitment}

Healthy control subjects $(n=21)$ were all volunteers. Patients with clinical diagnosis of COPD $(n=21)$ with any grade of severity according to the Global Initiative for Chronic Obstructive Lung Disease (GOLD) classification, who presented themselves for their regular visit at the Department of Pulmonology, Semmelweis University, were enrolled. ${ }^{1}$ Moreover, patients with persistent bronchial asthma $(n=44)$ were similarly recruited. The diagnosis of asthma was defined according to the current GINA classification. ${ }^{3}$ Patients with simultaneous diagnoses of asthma and COPD were included in the ACOS group $(n=20)$ based on the current GINA guideline $^{3}$ and if the following criteria were present:

- Previously diagnosed asthma, formerly proved reversibility, smokers or ex-smokers with $>10$ pack-years of smoking history, forced expiratory volume in 1 second $\left(\mathrm{FEV}_{1}\right)$ not reaching $80 \%$ of reference value after shortacting bronchodilator, and a ratio of $\mathrm{FEV}_{1}$ /forced vital capacity (FVC) $<70 \%$ or

- Smoker or ex-smoker ( $>10$ pack-years) COPD patients, who had notable reversibility after use of $400 \mu \mathrm{g}$ salbutamol and a ratio of $\mathrm{FEV}_{1} / \mathrm{FVC}<70 \%$.

All ACOS patients who presented themselves for their regular visit at the outpatient clinic and had no other uncontrolled chronic disease. All patients and controls were older than 18 years.

All patients with tuberculosis, any type of carcinoma, or patients who were receiving oxygen therapy or taking vitamin D supplementation were excluded. Cardiac and other comorbidities, smoking history, and COPD exacerbations were recorded from their medical files. Patients were asked about their respiratory symptoms and underwent a physical examination, chest X-ray, electrocardiography, and routine laboratory analysis.

For the presence of vitamin D insufficiency and deficiency, the following criteria were used:

Vitamin D sufficiency $>30 \mathrm{ng} / \mathrm{mL}$; vitamin D insufficiency $\leq 30 \mathrm{ng} / \mathrm{mL}$ and $\geq 20 \mathrm{ng} / \mathrm{mL}$; vitamin D deficiency $<20 \mathrm{ng} / \mathrm{mL}^{.14}$

\section{Lung function measurements}

Lung function measurements included $\mathrm{FVC}, \mathrm{FEV}_{1}, \mathrm{FEV}_{1}$ / FVC, forced expiratory flow between $25 \%$ and $75 \%$ of FVC (FEF25-75), total lung capacity (TLC), residual volume (RV), and Raw by means of electronic spirometer and body plethysmography (PDD-301/s; Piston Ltd., Budapest, Hungary) according to the American Thoracic Society guidelines. ${ }^{15}$ Three technically acceptable 
maneuvers were performed and the highest of them was used. Pulmonary function variables were expressed as a percentage of predicted values.

\section{Quality of life and asthma control}

The health status in COPD and ACOS patients was evaluated through a COPD assessment test (CAT) - Hungarian version. ${ }^{16}$ We measured COPD and ACOS patients' dyspnea severity using a modified Medical Research Council (mMRC) questionnaire. ${ }^{17}$ Patients were classified according to GOLD as having less symptoms $(\mathrm{CAT}<10)$ and breathlessness (mMRC grade $0-1)$ and more symptoms $($ CAT $\geq 10)$ and breathlessness (mMRC grade $\geq 2$ ). Asthma control was assessed by asthma control test (ACT), recommended by the current guidelines. ${ }^{3,18}$

\section{Laboratory procedures}

Blood samples were collected from all OLD patients and healthy volunteers. Serum total $25(\mathrm{OH}) \mathrm{D}$ concentrations were measured by the commercially available ELISA assay (DiaSorin S.p.A., Saluggia, Italy) according to the manufacturers' instructions. The detection limit of 25(OH)D was $4.0 \mathrm{ng} \cdot \mathrm{mL}^{-1}$. Blood cell counts and standard laboratory measurement results were included from patient's charts.

\section{Statistical analysis}

Statistical analysis was performed using Graph Pad Prism software 5 (GraphPad Software, Inc., La Jolla, CA, USA) and SPSS Statistics V22 (IBM Corporation, Armonk, NY, USA).
The results are expressed as the mean \pm standard error of mean if not stated otherwise. Not normally distributed data were $\log$ transformed. In case of not normally distributed data, comparisons between groups were evaluated using Kruskal-Wallis test, followed by Dunns post hoc comparison, for normally distributed data. One-way ANOVA test followed by Newman-Keuls post hoc test was used. Correlations between vitamin $\mathrm{D}$, lung function parameters, CAT, and ACT were determined by a Spearman's rank correlation when the data showed normal distribution and Pearson rank correlation with not normally distributed data. Univariate logistic regression analysis was performed in OLD groups to evaluate the risk factors associated with vitamin D deficiency. The identified risk factors in univariate analysis were included into multinomial logistic regression analyses to identify independent risk factors for vitamin D deficiency. Statistical power analyses were performed by G*Power 3.1 software (Universität Düsseldorf, Düsseldorf, Germany). ${ }^{19}$

\section{Results \\ Clinical characteristics}

The study had a cross-sectional design. Twenty-one healthy volunteers (control; 12 women and nine men), 44 patients with bronchial asthma (36 women and eight men), 21 COPD patients (ten women and eleven men), and 20 patients with ACOS (12 women and eight men) were recruited into the study. Baseline patient characteristics are summarized in Table 1, and medications used for their OLD are reported in Table 2.

Table I Clinical characteristics and sample collection data of the four study groups

\begin{tabular}{|c|c|c|c|c|}
\hline & Control & Asthma & COPD & Acos \\
\hline Number of patients (n) & 21 & 44 & 21 & 20 \\
\hline Female/male & $12 / 9$ & $36 / 8$ & $10 / 11$ & $12 / 8$ \\
\hline Age (years) & $38.00 \pm 3.34$ & $44.84 \pm 2.38$ & $66.33 \pm 2.63$ & $65.45 \pm 1.86$ \\
\hline BMI $\left(\mathrm{kg} / \mathrm{m}^{2}\right)$ & - & $26.80 \pm|.3|$ & $24.33 \pm 0.95$ & $29.12 \pm 1.45$ \\
\hline \multicolumn{5}{|l|}{ Smoking habits, n (\%) } \\
\hline Current smoker & $0(0)$ & I (2.25) & $4(19)$ & $5(25)$ \\
\hline Ex-smoker & I (4.75) & $2(4.5)$ & I5 (7I.25) & $14(70)$ \\
\hline Never-smoker & $20(95)$ & 41 (93.25) & $2(9.5)$ & I (5) \\
\hline GOLD category, n (\%) & - & - & II-IV & I-IV \\
\hline A & & & $0(0)$ & $3(15)$ \\
\hline B & & & $2(9.5)$ & $9(45)$ \\
\hline C & & & $0(0)$ & $0(0)$ \\
\hline D & & & $19(90.5)$ & $8(40)$ \\
\hline Allergic rhinitis or atopic nature, $\mathrm{n}(\%)$ & $0(0)$ & $34(77)$ & $0(0)$ & $10(50)$ \\
\hline Number of comorbidities, mean [range] & $0[0]$ & $0.34[0-4]^{\mathrm{a}}$ & $2.19[0-4]$ & $0.70[0-2]$ \\
\hline Sample collected in summer season, $\mathrm{n}(\%)$ & $2(9.5)$ & $3(6.75)$ & $5(24)$ & $0(0)$ \\
\hline
\end{tabular}

Notes: Data expressed as mean \pm SEM if not stated otherwise. a Only one asthmatic patient had four comorbidities.

Abbreviations: ACOS, asthma-COPD overlap syndrome; BMI, body mass index; COPD, chronic obstructive pulmonary disease; GOLD, Global Initiative for Chronic Obstructive Lung Disease; SEM, standard error of mean. 
Table 2 Medications and dose of ICS for patients with asthma, COPD, and ACOS

\begin{tabular}{|c|c|c|c|}
\hline & Asthma & COPD & Acos \\
\hline SABA/SAMA, n (\%) & $31(70)$ & $18(85)$ & $20(100)$ \\
\hline LAMA, n (\%) & $0(0)$ & $19(90)$ & $18(90)$ \\
\hline LABA, n (\%) & $34(77)$ & $20(95)$ & $20(100)$ \\
\hline Leukotriene inhibitors, $\mathrm{n}(\%)$ & $21(47)$ & $0(0)$ & $8(40)$ \\
\hline Total ICS use, n (\%) & $39(88)$ & $21(100)$ & $20(100)$ \\
\hline \multicolumn{4}{|c|}{ Daily dose of ICS (beclomethasone equivalent, $\mu \mathrm{g}$ ) } \\
\hline Low dose, n (\%), 200-500 $\mu \mathrm{g}$ & II (25) & $0(0)$ & $\mathrm{I}(5)$ \\
\hline Medium dose, $n(\%),>500-1,000 \mu g$ & $27(6 I)$ & $3(14)$ & $14(70)$ \\
\hline High dose, $n(\%),>I, 000 \mu g$ & I (2.25) & $18(85)$ & $5(25)$ \\
\hline
\end{tabular}

Abbreviations: $\mathrm{ACOS}$, asthma-COPD overlap syndrome; $\mathrm{COPD}$, chronic obstructive pulmonary disease; ICS, inhaled corticosteroid; LABA, long-acting beta agonist; LAMA, long-acting muscarinic antagonist; SABA, short-acting beta agonist; SAMA, short-acting muscarinic antagonist.

The mean age of participants in control and asthma groups was lower compared to COPD and ACOS groups (38.00 [range: 25-71] years and 44.84 [range: 22-85] years vs 66.33 [range: $43-86$ ] years and 65.45 [range: $50-83$ ] years; $P<0.0001$, respectively). The majority of controls and asthma patients were never-smokers $(95.00 \%$ and $93.25 \%)$, while there were mostly ex-smokers in the COPD and ACOS groups $(71.25 \%$ and $70.00 \%)$. The highest mean body mass index was observed in ACOS patients. A significant difference was only present between ACOS and COPD groups; however, body mass index had no effect on 25(OH)D level by binary logistic regression analysis (odds ratio [OR]: 1.018; 95\% confidence interval [CI]: $0.942-1.101 ; P=0.645)$. Most of the COPD patients were in GOLD class D $(90.50 \%)$, while $45 \%$ of ACOS patients were in class B and $40 \%$ in class D. Seventyseven percentage of asthmatic patients and $50 \%$ of ACOS patients were atopic. The highest number of comorbidities was noted in the COPD group. Seasonal changes may affect hormone levels; however, only few samples were collected in the summer season and had no significant effect on serum $25(\mathrm{OH}) \mathrm{D}$ level analyzed by binary logistic regression (OR: 1.265; 95\% CI: 0.295-5.430; $P=0.752$ ).

Short-acting beta agonist and/or short-acting muscarinic antagonist were prescribed to most of the patients for emergency use. Long-acting muscarinic antagonist was used by ACOS and COPD patients and long-acting beta agonist was used by many of the patients in all the three groups. Almost half of the asthma and ACOS patients $(47 \%$ and $40 \%$ ) used a leukotriene antagonist. Most of the patients used inhaled corticosteroids (ICSs) as listed in detail in Table 2.

\section{Change of serum 25(OH)D levels in study groups}

Sixty percentage (15/20) of ACOS, 76\% (16/21) of COPD, and $36 \%(16 / 44)$ of asthmatic patients had vitamin D deficiency defined as $<20 \mathrm{ng} / \mathrm{mL}$. As shown in Figure 1, the mean serum 25(OH)D level was significantly lower in ACOS and COPD groups compared to the asthma group $(16.86 \pm 1.79 \mathrm{ng} / \mathrm{mL}$ and $14.27 \pm 1.88 \mathrm{ng} / \mathrm{mL}$ vs $25.66 \pm 1.91 \mathrm{ng} / \mathrm{mL}$ - mean \pm standard error of mean; 15.85 [5.55-33.40] ng/mL and 10.80 [4.00-33.80] ng/mL vs 23.45 [8.43-63.10] ng/mL - median [range]). There was no significant difference between COPD and ACOS groups; likewise, no difference between the control group and asthma and ACOS groups was noted. Furthermore, serum 25(OH)D was not influenced by the daily inhaled ICS dose (Figure 1B). The statistical power of the comparable study groups was $>0.8$, indicating that the number of the patients was adequate to conclude real differences for $25(\mathrm{OH}) \mathrm{D}$ levels.
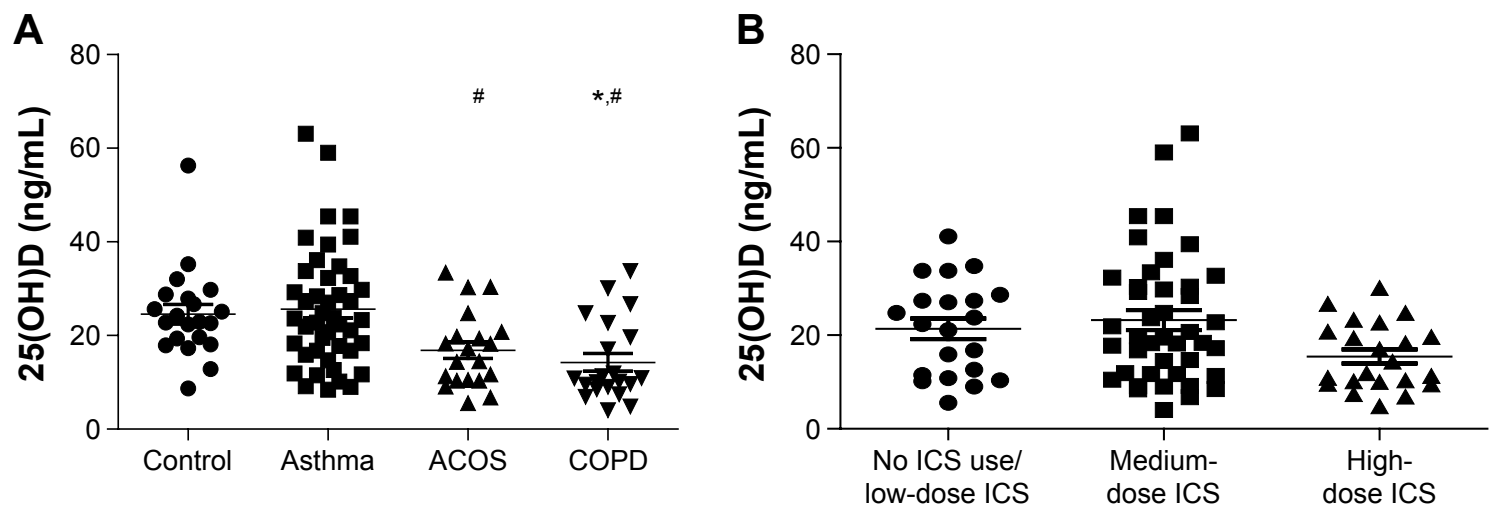

Figure I 25(OH)D levels in different patient groups and in OLD patients using different ICS doses.

Notes: (A) 25(OH)D levels measured in healthy individuals, asthma, ACOS, and COPD patients. (B) 25(OH)D levels in OLD patients using different doses of ICS. No significant differences were found between the study groups. $* P<0.05$ vs control. $\# P<0.05$ vs asthma.

Abbreviations: ACOS, asthma-COPD overlap syndrome; COPD, chronic obstructive pulmonary disease; $25(\mathrm{OH}) \mathrm{D}, 25-\mathrm{hydroxy}$ itamin D; ICS, inhaled corticosteroid; OLD, obstructive lung disease. 
Table 3 Lung function parameters, ACT, CAT, and mMRC tests of patients with asthma, COPD, and ACOS

\begin{tabular}{|c|c|c|c|c|c|}
\hline & \multirow[t]{2}{*}{ Asthma } & \multirow[t]{2}{*}{ Acos } & \multirow[t]{2}{*}{ COPD } & \multicolumn{2}{|l|}{$P$-value } \\
\hline & & & & Asthma vs ACOS & COPD vs ACOS \\
\hline $\mathrm{FEV}_{1}(\%$ pred $)$ & $87.61 \pm 2.70$ & $56.25 \pm 4.26$ & $32.67 \pm 3.93$ & $<0.000$ I & $<0.0001$ \\
\hline FVC (\% pred) & $98.34 \pm 2.43$ & $77.15 \pm 3.42$ & $56.05 \pm 3.69$ & $<0.000$ I & 0.0002 \\
\hline FEF25-75 (\% pred) & $63.49 \pm 3.95$ & $28.85 \pm 3.51$ & $13.76 \pm 1.26$ & $<0.000 \mathrm{I}$ & 0.0002 \\
\hline PEF (\% pred) & $83.4 I \pm 3.09$ & $48.75 \pm 3.87$ & $28.86 \pm 2.12$ & $<\mathbf{0 . 0 0 0 I}$ & $<0.000$ I \\
\hline Raw (\% pred) & $150.6 \pm 9.08$ & $|7| .1 \pm 20.95$ & $267.9 \pm 20.27$ & 0.29 & 0.0024 \\
\hline mMRC total score, mean [range] & - & $1.80[1-3]$ & $3.57[2-4]$ & - & $<0.0001$ \\
\hline ACT total score, mean [range] & $20.95[9-25]$ & $15.60[8-24]$ & - & $<0.000$ I & - \\
\hline CAT total score, mean [range] & - & $17.95[6-30]$ & $2|| .4[|2-3|]$ & - & 0.11 \\
\hline
\end{tabular}

Notes: Data expressed as mean \pm SEM if not stated otherwise. Significant differences are highlighted in bold.

Abbreviations: ACOS, asthma-COPD overlap syndrome; ACT, asthma control test; CAT, COPD assessment test; COPD, chronic obstructive pulmonary disease; FEF25-75, forced expiratory flow between $25 \%$ and $75 \%$ of FVC; FEV , forced expiratory volume in I second; FVC, forced vital capacity; mMRC, modified Medical Research Council; \% pred, \% predicted; Raw, airway resistance; SEM, standard error of mean.

\section{Comparison of lung function parameters and their correlation with serum $25(\mathrm{OH}) \mathrm{D}$ in OLD groups}

The results of lung function parameters for the respective OLD groups are listed in Table 3. The comparison between asthma vs ACOS groups showed a significant difference with regard to $\mathrm{FEV}_{1}, \mathrm{FVC}, \mathrm{FEF} 25-75$, and peak expiratory flow $(\mathrm{PEF}) \%$ predicted (all $P$-values were $<0.0001$ ) but did not show difference in Raw \% predicted $(P=0.29)$. In comparison to ACOS and COPD groups, significantly lower FEV ${ }_{1}$, FVC, FEF25-75, $\mathrm{PEF}$, and Raw\% predicted lung function parameters were observed in COPD patients (all $P$-values were $<0.001$ ).

With the Spearman's correlation analysis, a positive correlation was found between the serum 25(OH)D level and $\mathrm{FEV}_{1} \%$ predicted $(r=0.4433 ; P<0.0001 ;$ Figure $2 \mathrm{~A}), \mathrm{FVC} \%$ predicted $(r=0.3741 ; P=0.0004$; Figure $2 \mathrm{~B}), \mathrm{FEF} 25-75 \%$ predicted $(r=0.4179 ; P<0.0001$; Figure $2 \mathrm{C}$ ), and $\mathrm{PEF} \%$ predicted ( $r=0.4846 ; P<0.0001$; Figure 2D) in OLD patient groups. However, only the asthmatic group showed a positive correlation with PEF ( $r=0.3196 ; P=0.0345)$, when the data were separately analyzed (all $P$-values were $>0.05$ ).

\section{The relationship between serum $25(\mathrm{OH}) \mathrm{D}$ and quality of life scores in OLD patients}

ACT, CAT, and mMRC total scores are listed in Table 3. Our results showed a significant difference in the mMRC total score between ACOS and COPD groups $(P<0.0001)$, emphasizing that ACOS patients were less symptomatic (1.80 [1-3] vs 3.57 [2-4] - mean [range]).

Disease control in the asthmatic group was better than in the ACOS group (20.95 [9-25] vs 15.60 [8-24] - mean [range]). Additionally, we found a positive correlation between ACT total scores and serum 25(OH)D level $(r=0.3913 ; P=0.0018$; Figure $3 \mathrm{~A})$. The ACT total score showed no correlation in the asthmatic group, but a significant correlation between worse disease control, associated with lower serum 25(OH)D level, was observed in the ACOS group ( $r=0.4761 ; P=0.0339$; Figure 3B).

The mean CAT total scores showed no difference in COPD and ACOS groups ( $r=-0.1802 ; P=0.2597$; Figure 4A). A negative correlation of higher CAT scores with decreased serum 25(OH)D in ACOS group ( $r=-0.4446 ; P=0.0495$; Figure 4B) was noted; however, this tendency was not observed in the COPD group.

\section{Risk factors associated with vitamin D deficiency}

Linear regression analysis showed a correlation between the diagnosis of OLD and vitamin D deficiency, indicating that the clinical diagnosis of COPD and ACOS are risk factors for vitamin D deficiency (Table 4).

In respect of the clinical parameters of OLD patients, age, $\mathrm{FEV}_{1}$ and $\mathrm{PEF}<80 \%$ predicted, ACT total score, atopic nature, low-dose ICS use, and clinical diagnosis of different OLD showed a correlation to vitamin D deficiency (Table 4). Only the atopic nature reached a statistically significant level $(P=0.032)$, as an independent risk factor for vitamin $D$ deficiency, by multivariate overall analysis of the clinical parameters of OLD patients (Table 4).

\section{Discussion}

To our knowledge, this study was the first to investigate the serum 25(OH)D level in ACOS and its connections with clinical parameters in this lung disorder. The prevalence of vitamin D deficiency was high, both in ACOS and COPD groups, while asthma group showed mainly vitamin D insufficiency. In our study, many healthy volunteers of the control 

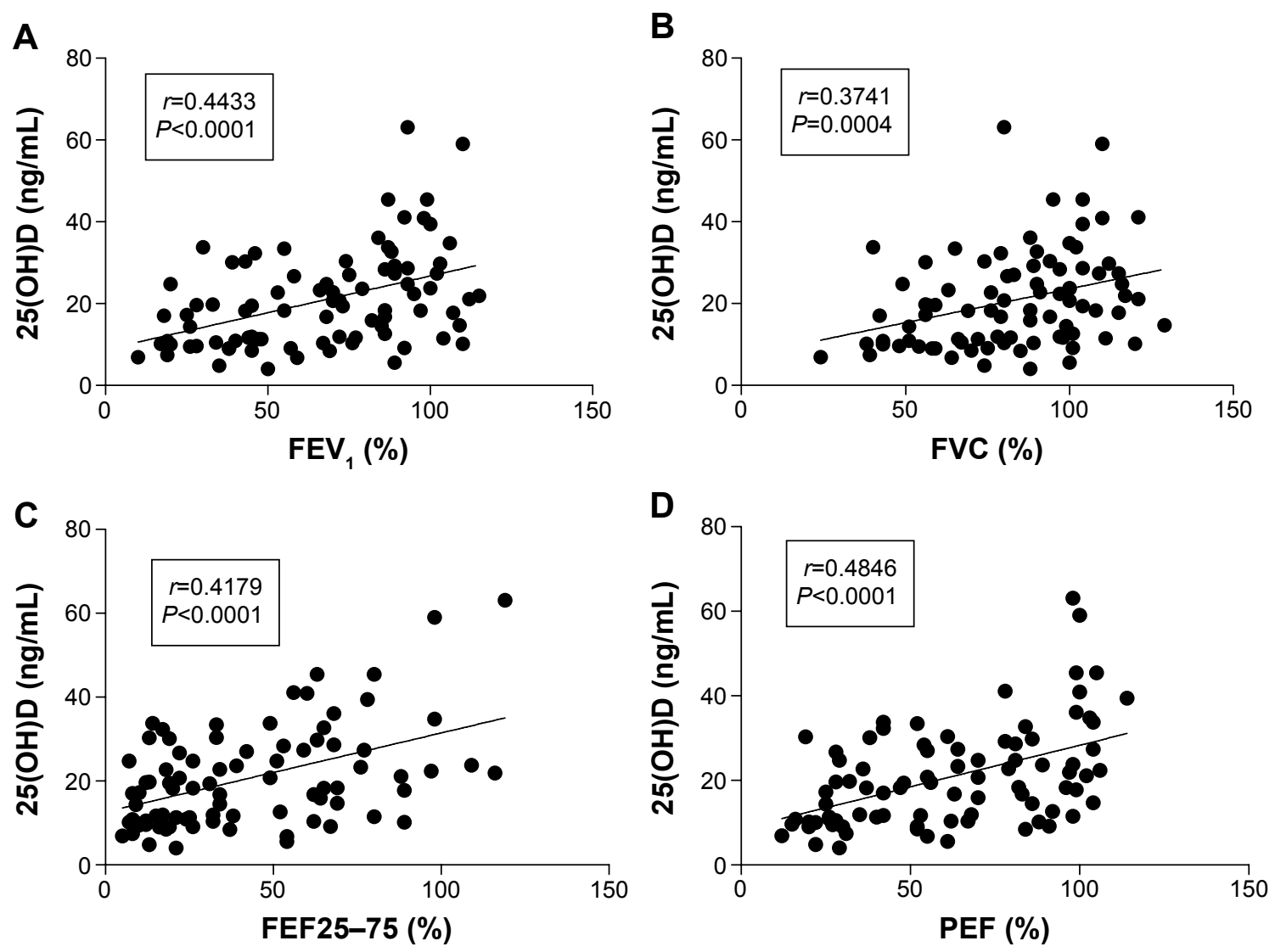

Figure 2 Correlations between 25(OH)D levels and lung function parameters in OLD patients.

Notes: Positive correlation between 25(OH)D levels to FEV 1 (\% pred) (A), FVC (\% pred) (B), FEF25-75 (\% pred) (C), and PEF (\% pred) (D).

Abbreviations: FEF25-75, forced expiratory flow between $25 \%$ and $75 \%$ of FVC; FEV , forced expiratory volume in I second; FVC, forced vital capacity; $25(\mathrm{OH}) \mathrm{D}$, 25 hydroxyvitamin D; \% pred, \% predicted; OLD, obstructive lung disease; PEF, peak expiratory flow.

group also had vitamin D insufficiency, suggesting that this condition may be overrepresented in the healthy Hungarian population. There are data showing that $50 \%$ of women after menopause had vitamin D insufficiency in winter and fall seasons and $70 \%$ in spring. However, representative studies are not available about the vitamin D status of the Hungarian population. ${ }^{20}$ Our data demonstrated a positive correlation between lung function parameters and 25(OH)D levels when analyzing all patients with OLD. However, these correlations were not detectable in separately analyzed asthma and COPD patient groups. In contrast, a correlation between the loss of asthma control and disease severity in ACOS with
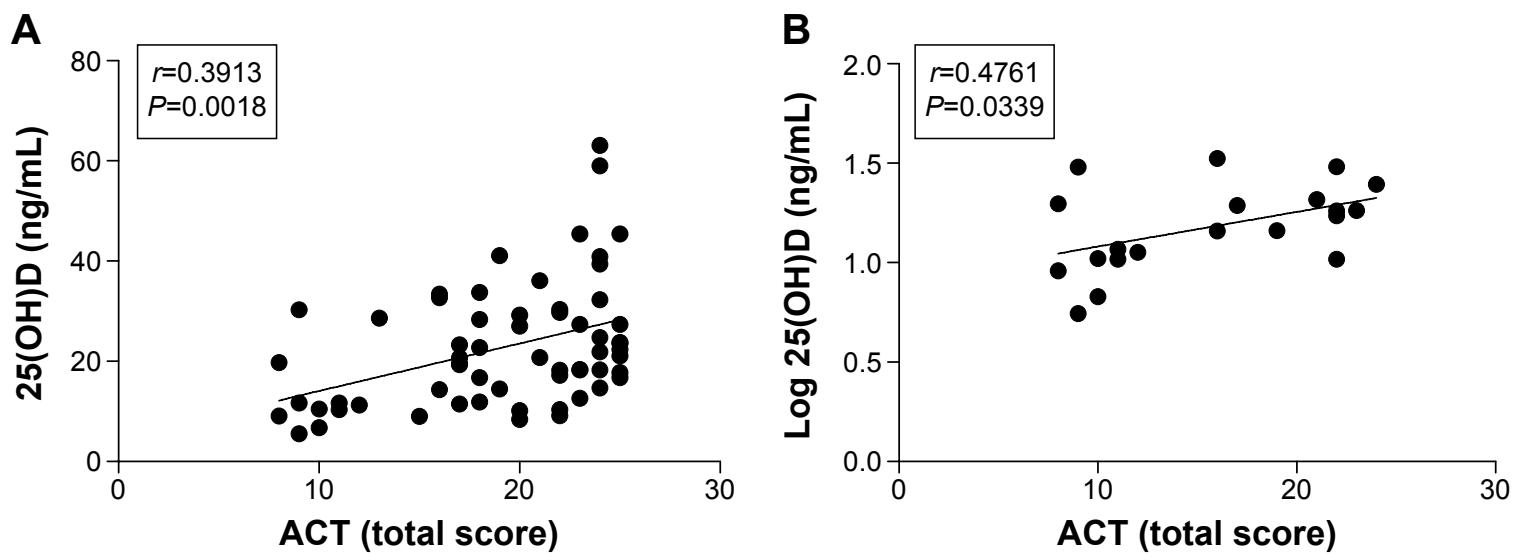

Figure 3 Correlation between 25(OH)D levels and ACT total score.

Notes: (A) Positive correlation between ACT total score and 25(OH)D levels in ACOS and asthma study groups. (B) Positive correlation between ACT total score and 25(OH)D levels in ACOS group.

Abbreviations: ACT, asthma control test; ACOS, asthma-COPD overlap syndrome; COPD, chronic obstructive pulmonary disease; $25(\mathrm{OH}) \mathrm{D}$, 25-hydroxyvitamin D. 

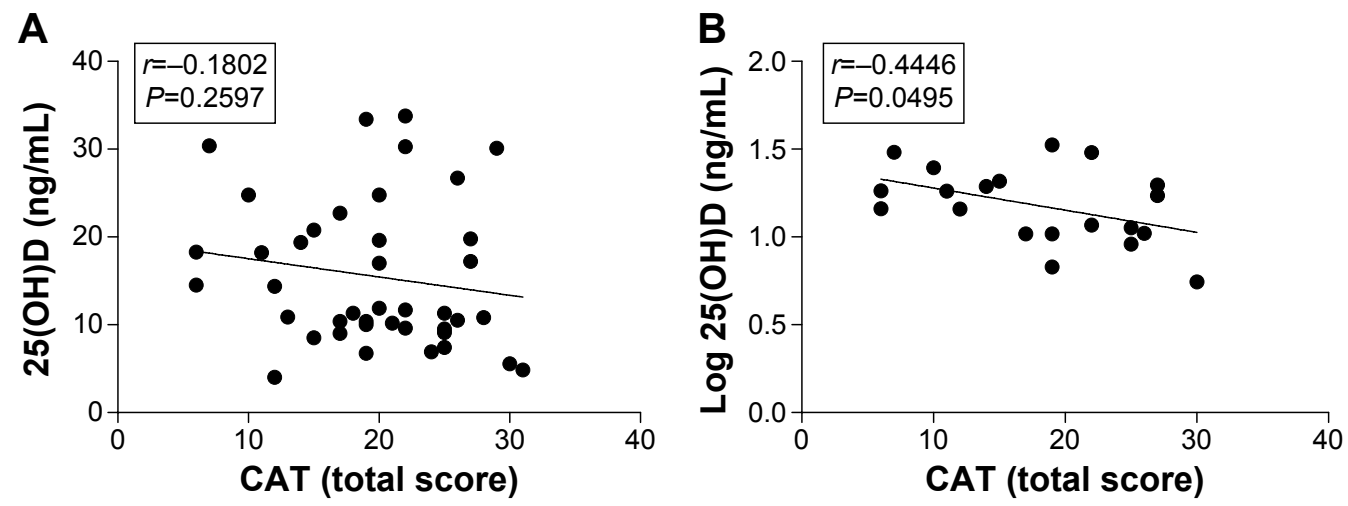

Figure 4 Correlation between $25(\mathrm{OH}) \mathrm{D}$ levels and CAT total score.

Notes: (A) No association between CAT total score and 25(OH)D levels in ACOS and COPD groups. (B) Negative correlation between CAT total score and 25(OH)D levels in ACOS group.

Abbreviations: ACOS, asthma-COPD overlap syndrome; CAT, COPD assessment test; COPD, chronic obstructive pulmonary disease; 25(OH)D, 25-hydroxyvitamin D.

decreasing 25(OH)D levels can be implicated (according to the vitamin $\mathrm{D}, \mathrm{ACT}$, and CAT data).

In our study cohort, patients with COPD and ACOS were older than asthmatic and control patients. It is known that there is a high prevalence of suboptimal vitamin $\mathrm{D}$ level in older men and women, and the recommended dose of vitamin D supplementation in elderly subjects with osteoporosis or on steroid treatment and vitamin D deficiency is greater. ${ }^{21}$ In most studies, the prevalence and severity of hypovitaminosis $\mathrm{D}$ in patients with COPD is higher than that in control populations. ${ }^{6,22}$ In addition, the National Health and Nutrition Examination Survey III (NHANES III) study suggests that vitamin D status might directly influence the lung function even after adjustment for age. ${ }^{8}$ However, using multiple regression analysis, age did not affect the vitamin D deficiency in OLD groups, suggesting that age is not the reason for vitamin D deficiency in our patient groups. In contrast, recent work has shown that intermittent bolus vitamin D supplementation added to a daily low-dose D3 regimen increased the risk and duration of upper respiratory infections. Correction of vitamin D deficiency in ACOS and COPD patients could lead to better lung function and quality of life; however, it might also increase the risk of respiratory tract infections and subsequent acute exacerbations. ${ }^{23}$

Severe COPD has a major impact on the quality of life, leading to the fact that patients often spend less time outdoors due to exercise-induced dyspnea and subsequent decreased exercise capacity. It is known that reduced outdoor activity is a risk factor for vitamin D deficiency, and observational studies in the elderly have demonstrated a link between declined physical performance and vitamin D status. ${ }^{14,24}$ Jung et al showed that the exercise capacity in COPD patients with vitamin $\mathrm{D}$ deficiency tended to be decreased, but they did not find a link between vitamin D level and quality of life. ${ }^{25}$
These results are in agreement with other studies confirming low levels of D vitamin in COPD patients. ${ }^{26,27}$ According to our data, ACOS patients had better lung function parameters and $\mathrm{mMRC}$ scores than COPD patients, suggesting that their overall functional status may, perhaps, be better. As compared to the healthy population, ACOS patients also have decreased exercise performance, which may play an important role in the detection of vitamin D deficiency.

CAT has been developed to quantify COPD impact in routine clinical practice, and it has become one of the main tools in the recognition of health status in the disease. ${ }^{28} \mathrm{In}$ our study, CAT scores did not differ in COPD and ACOS patients; however, we did find an association between CAT scores and 25(OH)D level in ACOS group, but not in COPD patients. This observation supports the hypothesis that vitamin D level may have a stronger effect on health status in ACOS patients, than in COPD subjects. This could be explained by better quality of life test scores, lung function parameters, and less comorbidities observed in ACOS patients. Other study showed worse CAT scores for ACOS patients, but it is important to note that most of the COPD patients in our study group were in category D. ${ }^{29}$ To avoid high morbidity, optimal disease control in asthma would be crucial; however, blood biomarkers or clinical parameters to identify patients at risk are not available. ${ }^{3}$ Mean ACT scores were worse in ACOS than in the asthma group. In our patients with asthma (asthma and ACOS), ACT scores demonstrated a correlation with $25(\mathrm{OH}) \mathrm{D}$ level. But separately analyzing the two groups (asthma vs ACOS), there was a positive correlation between poorer disease control and lower 25(OH)D levels only in ACOS patients. In previous follow-up studies, improvement in disease control of asthmatic patients who received vitamin D supplementation was observed. ${ }^{30,31}$ As ACOS patients had lower vitamin D 
Table 4 Univariate and multivariate logistic regressions showing the risk factors associated with vitamin D deficiency

\begin{tabular}{|c|c|c|c|}
\hline & \multicolumn{3}{|c|}{ Vitamin D deficiency } \\
\hline & OR & 95\% Cl (Ref) & $P$-value \\
\hline \multicolumn{4}{|l|}{ Univariate } \\
\hline \multicolumn{4}{|l|}{ Obstructive pulmonary disease } \\
\hline COPD & 3.406 & $(1.114-10.414)$ & 0.032 \\
\hline ACOS & 3.094 & $(1.007-9.509)$ & 0.049 \\
\hline Bronchial asthma & 0.184 & $(0.072-0.472)$ & $<0.0001$ \\
\hline \multicolumn{4}{|l|}{ ICS use } \\
\hline Low-dose ICS use & 0.22 & $(0.055-0.880)$ & 0.032 \\
\hline Medium-dose ICS use & 0.792 & $(0.336-1.865)$ & 0.594 \\
\hline High-dose ICS use & 2.753 & $(0.953-7.948)$ & 0.061 \\
\hline \multicolumn{4}{|l|}{ Clinical parameters } \\
\hline Sample collected in summer season & 1.265 & $(0.295-5.430)$ & 0.752 \\
\hline Age & 1.035 & $(1.007-1.063)$ & 0.014 \\
\hline Sex & 1.016 & $(0.405-2.545)$ & 0.0974 \\
\hline BMI & 1.018 & $(0.942-1.101)$ & 0.645 \\
\hline $\mathrm{FEV}_{1}(\%$ pred $)<80 \%$ & 4.01 & $(1.600-10.053)$ & 0.003 \\
\hline PEF (\% pred) $<80 \%$ & 3.273 & $(1.294-8.274)$ & 0.012 \\
\hline ACT total score & 0.859 & $(0.766-0.963)$ & 0.009 \\
\hline ACT $\leq 20$ points & 2.746 & $(0.967-7.795)$ & 0.058 \\
\hline CAT total score & 1.028 & $(0.92 I-1.148)$ & 0.618 \\
\hline CAT $\geq 20$ points & 1.214 & $(0.291-5.060)$ & 0.79 \\
\hline CAT $\geq 17$ points & 1.232 & $(0.255-5.944)$ & 0.715 \\
\hline CAT $\geq 10$ points & 1.611 & $(0.130-19.909)$ & 0.71 \\
\hline $\mathrm{mMRC}$ & 1.214 & $(0.64 I-2.300)$ & 0.551 \\
\hline $\mathrm{mMRC} \geq 2$ points & 3.467 & $(0.709-16.938)$ & 0.125 \\
\hline Atopic nature & $4.5 \mathrm{II}$ & $(1.778-11.448)$ & 0.002 \\
\hline Eosinophil cell count (G/L) & 0.322 & $(0.053-1.942)$ & 0.216 \\
\hline Eosinophil cell count $>0.2(\mathrm{G} / \mathrm{L})$ & 0.662 & $(0.270-1.621)$ & 0.366 \\
\hline \multicolumn{4}{|l|}{ Multivariate } \\
\hline \multicolumn{4}{|l|}{ Clinical parameters } \\
\hline Age & 1.001 & $(0.954-1.049)$ & 0.98 \\
\hline $\mathrm{FEV}_{1}$ (\% pred) $<80 \%$ & 0.659 & $(0.099-4.375)$ & 0.666 \\
\hline PEF (\% pred) $<80 \%$ & 3.505 & $(0.497-24.705)$ & 0.208 \\
\hline ACT total score & 1.107 & $(0.95 \mathrm{I}-\mathrm{I} .290)$ & 0.19 \\
\hline Atopic nature & 0.176 & $(0.036-0.862)$ & 0.032 \\
\hline Low-dose ICS use & 4.77 & $(0.550-41.400)$ & 0.156 \\
\hline OLD diagnosis & 1.618 & $(0.880-2.978)$ & 0.122 \\
\hline
\end{tabular}

Note: Significant differences are highlighted in bold.

Abbreviations: ACOS, asthma-COPD overlap syndrome; ACT, asthma control test; BMI, body mass index; CAT, COPD assessment test; $\mathrm{Cl}$, confidence interval; COPD, chronic obstructive pulmonary disease; $\mathrm{FEV}_{1}$, forced expiratory volume in I second; ICS, inhaled corticosteroid; mMRC, modified Medical Research Council; OLD, obstructive lung disease; OR, odds ratio; \% pred, \% predicted; Ref, reference; $P E F$, peak expiratory flow.

level and worse disease control, vitamin D supplementation may improve symptoms in this population.

There are several studies analyzing the relationship between vitamin D level and lung function parameters. In our study, a significant association was found between serum $25(\mathrm{OH}) \mathrm{D}$ levels and lung function parameters in OLD groups. However, when analyzing data for single disease groups, we did not observe these results except for PEF\% in the asthma group. It is possible that a large number of patients would have created significant association with spirometric values similar to previous studies in other OLD groups as well. ${ }^{10}$ Limitations of our study are the cross-sectional design of a single hospital center and the limited number of patients. COPD group consisted of only severe (D category) patients. However, the power of the study was sufficient to show real differences. A longitudinal follow-up of this patient group is important, as quality of life measurements and its association with treatable disorders (vitamin D deficiency) could contribute to better patient care and improved long-term outcomes.

\section{Conclusion}

In the near past, ACOS patients were mainly treated as severe uncontrolled asthma or symptomatic COPD patients. Defining them as a separate patient group, data on patient characteristics and comorbid conditions are desperately warranted. ${ }^{32}$ Our data demonstrated that vitamin D deficiency is a common feature of ACOS patients in a continental climate country and is similarly low as seen in severe COPD patients. In our study, 25(OH)D level showed association with lung function parameters and ACT in OLD patients. An important clinical message is that ACOS patients have much worse quality of life measures when using CAT and ACT, and our data indicate that data on simultaneous quality of life measurements are important. Though vitamin D deficiency correlated with ACT and CAT scores in ACOS patients, this association was not present in asthma or COPD groups. These results highlight the importance of $25(\mathrm{OH}) \mathrm{D}$ level in ACOS and patient-related quality of life measurements. Vitamin D deficiency is treatable, so future studies examining the effect of supplementation are needed.

\section{Acknowledgment}

The skillful technical assistance of Edina Bíró in ELISA measurements is acknowledged.

\section{Disclosure}

The authors report no conflicts of interest in this work.

\section{References}

1. Global Initiative for Chronic Obstructive Lung Disease (GOLD). National Heart Lung and Blood Institute, National Institutes of Health. GOLD Report. Global Strategy for Diagnosis, Management and Prevention of COPD. Bethesda, NIH 2009; 2015. Available from: www.goldcopd.org. Accessed May 24, 2015.

2. European Respiratory Society. European Lung White Book. In: Gibson GJ, Loddenkemper R, Sibille Y, Lundbäck B, Fletcher M, editors; 2013. Available from: www.erswhitebook.org. Accessed March 12, 2015.

3. Global Initiative for Asthma. Available from: http://www.ginasthma. org. Accessed May 25, 2015.

4. Rabe KF, Adachi M, Lai CK, et al. Worldwide severity and control of asthma in children and adults: the global asthma insights and reality surveys. J Allergy Clin Immunol. 2004;114(1):40-47. 
5. Barrecheguren M, Esquinas C, Miravitlles M. The asthma-chronic obstructive pulmonary disease overlap syndrome (ACOS): opportunities and challenges. Curr Opin Pulm Med. 2015;21(1):74-79.

6. Janssens W, Bouillon R, Claes B, et al. Vitamin D deficiency is highly prevalent in COPD and correlates with variants in the vitamin D-binding gene. Thorax. 2010;65:215-220.

7. Persson LJ, Aanerud M, Hiemstra PS, Hardie JA, Bakke PS, Eagan TM. Chronic obstructive pulmonary disease is associated with low levels of vitamin D. PLoS One. 2012;7:e38934.

8. Black PN, Scragg R. Relationship between serum 25-hydroxyvitamin D and pulmonary function in the third national health and nutrition examination survey. Chest. 2005;128(6):3792-3798.

9. Cassim R, Russell MA, Lodge CJ, Lowe AJ, Koplin JJ, Dharmage SC. The role of circulating 25 hydroxyvitamin $\mathrm{D}$ in asthma: a systematic review. Allergy. 2015;70:339-354.

10. Sutherland ER, Goleva E, Jackson LP, Stevens AD, Leung DY. Vitamin D levels, lung function and steroid response in adult asthma. Am J Respir Crit Care Med. 2010;181:699-704.

11. Devereux G, Litonjua AA, Turner SW, et al. Maternal vitamin D intake during pregnancy and early childhood wheezing. Am J Clin Nutr. 2007; 85:853-859.

12. Cremers E, Thijs C, Penders J, Jansen E, Mommers M. Maternal and child's vitamin D supplement use and vitamin level in relation to childhood lung function. The KOALA Birth Cohort Study. Thorax. 2011;66:474-480.

13. Zosky GR, Berry LJ, Elliott JG, James AL, Gorman S, Hart PH. Vitamin D deficiency causes deficits in lung function and alters lung structure. Am J Respir Crit Care Med. 2011;183:1336-1343.

14. Holick MF. Vitamin D deficiency. New Eng J Med. 2007;357(3): 266-281.

15. Miller MR, Hankinson J, Brusasco V, et al. Standardisation of spirometry. Eur Respir J. 2005;26:319-338.

16. Jones PW, Harding G, Berry P, Wiklund I, Chen WH, Kline Leidy N. Development and first validation of the COPD assessment test. Eur Respir J. 2009;34:648-654.

17. Bestall JC, Paul EA, Garrod R, Garnham R, Jones PW, Wedzicha JA. Usefulness of the Medical Research Council (MRC) dyspnoea scale as a measure of disability in patients with chronic obstructive pulmonary disease. Thorax. 1999;54:581-586.

18. www.tudogyogyasz.hu. Asztma diagnosztikájának, kezelésének és orvosi gondozásának alapelveiröl felnőttkorban. [Diagnosis, treatment and management guideline of asthma in adults]. Available from: http:// tudogyogyasz.hu/upload/tudogyogyasz/document/000819_asztma. pdf?web_id=. Accessed June 12, 2015.

19. Faul F, Erdfelder E, Lang AG, Buchner A. G*Power 3: a flexible statistical power analysis program for the social, behavioral, and biomedical sciences. Behav Res Methods. 2007;39:175-191.
20. Takács I, Benkő I, Toldy E, et al. Hazai konszenzus a D-vitamin szerepéről a betegségek megelőzésében és kezelésében [Hungarian consensus regarding the role of vitamin $\mathrm{D}$ in the prevention and treatment of diseases]. Orv Hetil. 2012;153(suppl):S5-S26.

21. Dawson-Hughes B, Mithal A, Bonjour JP, et al. IOF position statement: vitamin D recommendations for older adults. Osteoporos Int. 2010;21: 1151-1154.

22. Mekov E, Slavova Y, Tsakova A, et al. Vitamin D deficiency and insufficiency in hospitalized COPD patients. PLoS One. 2015;10(6): e0129080.

23. Martineau AR, Hanifa Y, Witt KD, et al. Double-blind randomized controlled trial of vitamin D3 supplementation for the prevention of acute respiratory infection in older adults and their carers (ViDiFlu). Thorax. Epub 2015 Jun 10.

24. Wicherts IS, van Schoor NM, Boeke AJ, et al. Vitamin D status predicts physical performance and its decline in older persons. J Clin Endocrinol Metab. 2007;92(6):2058-2065.

25. Jung JY, Kim YS, Kim SK, et al. Relationship of vitamin D status with lung function and exercise capacity in COPD. Respirology. 2015; 20(5):782-789.

26. Hashim Ali Hussein S, Nielsen LP, Konow Bogebjerg Dolberg M, Dahl R. Serum magnesium and not vitamin D is associated with better QoL in COPD: a cross-sectional study. Respir Med. 2015;109(6): 727-733.

27. Romme EA, Rutten EP, Smeenk FW, Spruit MA, Menheere PP, Wouters EF. Vitamin D status is associated with bone mineral density and functional exercise capacity in patients with chronic obstructive pulmonary disease. Ann Med. 2013;45(1):91-96.

28. Lopez-Campos JL, Fernandez-Villar A, Calero-Acuña C, et al; On-Sint Study Group. Evaluation of the COPD assessment test and GOLD patient types: a cross-sectional analysis. Int J Chron Obstruct Pulmon Dis. 2015;10:975-984.

29. Suzuki T, Tada Y, Kawata N, et al. Clinical, physiological, and radiological features of asthma-chronic obstructive pulmonary disease overlap syndrome. Int J Chron Obstruct Pulmon Dis. 2015;10:947-954.

30. de Groot JC, van Roon EN, Storm H, et al. Vitamin D reduces eosinophilic airway inflammation in nonatopic asthma. J Allergy Clin Immunol. 2015;135(3):670-675.

31. Columbo M, Panettieri RA Jr, Rohr AS. Asthma in the elderly: a study of the role of vitamin D. Allergy Asthma Clin Immunol. 2014;10(1):48.

32. Nielsen M, Barnes CB, Ulrik CS. Clinical characteristics of the asthma COPD overlap syndrome - a systematic review. Int J Chron Obstruct Pulmon Dis. 2015;10(1):1443-1454.
International Journal of COPD

\section{Publish your work in this journal}

The International Journal of COPD is an international, peer-reviewed journal of therapeutics and pharmacology focusing on concise rapid reporting of clinical studies and reviews in COPD. Special focus is given to the pathophysiological processes underlying the disease, intervention programs, patient focused education, and self management protocols.

\section{Dovepress}

This journal is indexed on PubMed Central, MedLine and CAS. The manuscript management system is completely online and includes a very quick and fair peer-review system, which is all easy to use. Visit http://www.dovepress.com/testimonials.php to read real quotes from published authors. 